\title{
Empowering Women, Infants and Children (WIC) Recipients
}

\author{
Phoneshia Wells \\ Health Services Department, University of Southern Indiana, Evansville, United States of America
}

Email address:

pwells@usi.edu

\section{To cite this article:}

Phoneshia Wells. Empowering Women, Infants and Children (WIC) Recipients. International Journal of Vocational Education and Training Research. Vol. 5, No. 1, 2019, pp. 33-37. doi: 10.11648/j.ijvetr.20190501.16

Received: April 1, 2019; Accepted: May 15, 2019; Published: June 11, 2019

\begin{abstract}
Women, Infants, and Children (WIC) is a federal program available to expectant and post-partum women of low economic status. The WIC program provides education, nutritional supplements, and provides health and social referrals to recipients. The overall purpose of this study was to create a program that would inform, educate, and empower recipients so they could utilize the WIC EBT card to its full potential by obtaining all items covered and available to them. A descriptive, pre-experimental, one group pretest -posttest design was utilized. Additionally, the researcher administered survey questions to determine what challenges recipients experience, comfort level using the voucher, and other information pertinent to successful use of the WIC EBT card. Consequently, two 45 minutes educational sessions were provided to recipients regarding the approved foods with an emphasis regarding brands and sizes. Following the in-service classes, significant changes were noted in staff knowledge $(n=8)$ regarding WIC approved items (95\% confidence interval and a significant value of.029). This indicated there was a change in knowledge when comparing the number of correct responses selected on the pre-test to the correct responses selected on the post-test. After a thorough analysis, the investigator discovered that Women, Infant, and Children (WIC) recipients were comfortable utilizing their WIC EBT card; however, there was a need for additional education on the products covered by the WIC EBT card.
\end{abstract}

Keywords: Women, Infant, and Children (WIC), Recipients, WIC EBT Card

\section{Introduction}

The Special Supplemental Nutrition Program for Women, Infants, and Children (WIC) was piloted in 1972 and established as an organization in 1974. This program is extended to women during pregnancy and postpartum. In addition, infants ( 0 to 12 months) and children (1-5 years) are also afforded WIC assistance. WIC provides nutritional supplements, education, and health and social services referrals to recipients who are of low economic status [1]. WIC was originally established to prevent under-nutrition and mico-nutrient deficiencies in those consuming inadequate calories and continues to support adequate nutrition. However, there was a shift in 2005, Institute of Medicine (IOM) report WIC Food Packages: Time for a Change challenged WIC to offer a more balanced approach to malnutrition, namely to reduce the elements of the food package that contribute to overweight and obesity without compromising key nutrients/micronutrients often absent in the diet [2]. In addition, WIC is one of the largest nutritional programs provided solely by the federal government and accounts for about half of all infants born in the United States [3]. In 2014, WIC cost $\$ 6.2$ billion and served an estimated 8.2 million individuals. The average food package equates to about $\$ 45$ a month [4]. The population served by WIC included approximately 2.0 million infants, or about half of all infants born in the US that year [5].

Because of the rising food and formula costs, one would assume WIC enrollment is expanding throughout the United States. Despite the health and nutritional benefits of the WIC program, participation in the WIC program has declined since 2009. Although WIC participation is extremely high in the first year of life, it drops significantly in early childhood [6]. From 2009 to 2015, WIC participation decreased from $62.9 \%$ of eligible recipients participating to $52.7 \%$ of eligible recipients participating [7]. In fact, there remains a sizable number of individuals who are eligible for the program but do not apply [3]. Eligible individuals who do not apply for WIC may be at risk for adverse health outcomes. The relationship between poor dietary intake and adverse health outcomes has been well established. For example, diets rich 
in fruits, vegetables, and whole grains and low in saturated fat have been associated with a lower risk of many conditions including obesity, cardiovascular disease, diabetes, and some cancers. Low-income and minority populations are disproportionately at risk for poor dietary intake [8]. Poor diet quality is one of the biggest risk factors for death and morbidity in the United States, responsible for more than 600,000 deaths in 2010 alone [9]. If these issues are not addressed in childhood it is likely that low-income children will enter adulthood at a disadvantage, as the consequences of poor health (in childhood) are often persistent [10]. As a result, WIC provides participants seasonal Farmers' Market Nutrition Program (FMNP) vouchers to purchase fruits and vegetables (FV) at farmers' markets and monthly cash value vouchers (CVV) redeemable at farmers' markets. Despite the promise of FMNP vouchers and CVV for improving FV access among WIC participants, voucher redemption rates are low [11].

Evidence suggest consuming the proper nutritional foods are essential to the health and development of the unborn baby. In a study conducted in Bangladesh, it was noted that infants had greater motor development when the expectant mothers engaged in food supplementation [12]. Expectant mothers need to consume foods of high nutritional value. Doing so improves and enhances growth and development in infants. In fact, expectant women who are malnourished should be strategically targeted to ensure they have early exposure to healthy and nutritious foods [12]. Lower birthweight children are at higher risk of mortality and lifelong disabilities which is often the result of malnourished expectant mothers [13]. In addition, to providing checks for food, WIC may contribute to better birth outcomes by reducing stress about accessing food, referring women to earlier PNC, and providing education that may reduce risk behaviors, like smoking [4].

Based on the Institute of Medicine's recommendations in 2009, the USDA implemented new WIC food packages. This was the first revision since the development of WIC in 1980. The revisions were correlated with the 2005 Dietary Guidelines of Americans. Accordingly, WIC focused on reducing intake of saturated fats and sodium while increasing consumption of fiber, vitamin E, and iron. In addition, fruits, vegetables, and whole grains were added and fruit juices were reduced by $50 \%$. In efforts to reduce cholesterol and saturated fat the amount of eggs, cheese, and milk was reduced and whole milk was offered only for those 2 years old and younger [8].

Many Americans consume foods that are of low or of no nutritional value because of limited accessibility to healthier options. The changes to WIC helped to improve the availability of products by offering WIC approved foods in local markets and grocery stores. When interviewing vendors, most agreed they were pleased to be able to offer foods to WIC recipients [8]. However, many stated some customers expressed frustration because they could only purchase certain items with the voucher. In fact, most of the vendors stated their main challenge was explaining the new rules to customers and felt there was a knowledge gap between customers and the new package regulations [8]. Most agreed that further education could help to improve such concerns [8]. To date, limited studies have focused on ensuring participants are educated thoroughly on the items available via the WIC EBT card.

In this study, the researcher partnered with the WIC Office, Principle Rob Carrol, and the Audubon Kids Zone Community Center of Henderson, Kentucky to recruit WIC recipients. The researcher hypothesized that providing education would improve participant's knowledge of the items covered and improve confidence level when shopping with the WIC EBT card. Furthermore, research indicates that WIC Participation has a positive impact on household food security status. So, it is imperative to implement education that will sustain or improve the retrieval of WIC items [14].

\section{Method}

\subsection{Study Design}

This research is a descriptive, pre-experimental, one group pretest -posttest design. The researcher administered a pretest to recipients prior to the study to gather baseline data. Likewise, the researcher administered survey questions to determine what challenges recipients face, comfort level using the voucher, and other information pertinent to successful use of the WIC EBT card.

\subsection{Intervention}

There were two 45-minute educational classes that consisted of the following:

a) the first class included an educational session reviewing the items covered via the WIC EBT program. The education included the researcher presenting information on the brands and correct sizes allowed for redemption. However, also allowing participants to identify the appropriate brands and sizes of items covered.

b) the second class included mocked shopping experiences and working in teams identifying items covered.

\subsection{Procedures}

Following the University of Southern Indiana Institutional Review Board Approval (IRB), participants were recruited. Flyers were posted in local stores and community centers informing WIC recipients of the opportunity to participate in voluntary classes (study). The Henderson, KY WIC office mailed letters informing all WIC recipients of the classes offered. Participants that attended the classes were read the terms of the study and signed a consent form stating agreement to the terms and informed that withdrawal was possible at any stage during the study. After such, anonymously identification codes were generated for the participants in order to compare pre-test data to the post-test data.

The educational sessions were conducted for WIC participants explaining how the WIC EBT card system works and what specific items are included for purchase within the 
WIC EBT card. All WIC recipients in Henderson, KY were invited to attend both optional training classes. Prior to education, recipients were administered a pre-test. Likewise, recipients were administered a survey to obtain information such as confidence level when shopping, areas of greatest concerns and etc.

At the completion of the study, the post-test was administered to recipients to gather post data. The post-test data was used to evaluate if there was a change in knowledge after attending the classes in comparison to the knowledge accessed at baseline.

\subsection{Research Question}

Is there a change in participant's knowledge and confidence related to shopping after the intervention?

\section{Result}

A total of eight recipients $(n=8)$ completed both the pretest and post-test and attended both classes. Following the educational sessions, significant changes were noted in participant's knowledge regarding WIC approved items $(95 \%$ confidence interval and a significant value of.029, Table 2). This indicated there was a change in knowledge when comparing the number of correct responses selected on the pre-test to the correct responses selected on the post-test (Table 1). A gap in knowledge of items covered via the WIC EBT Card was noted among recipients.

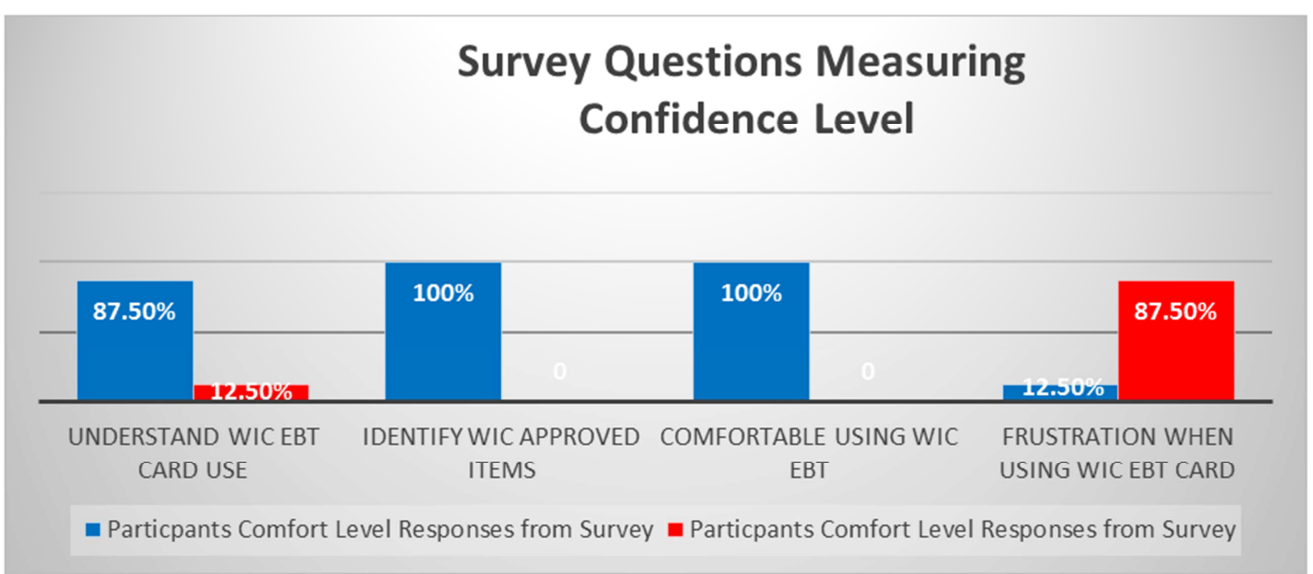

Figure 1. Summary of responses of question assessing confidence level when shopping Assessing participant comfort level when shopping with the WIC EBT Card

Table 1. Summary of correct responses by question.

\begin{tabular}{lll}
\hline Question & Pre & Post \\
\hline 7 & $100 \%$ & $87.5 \%$ \\
8 & $75 \%$ & $61.5 \%$ \\
9 & $37.5 \%$ & $75 \%$ \\
10 & $75 \%$ & $100 \%$ \\
11 & $62.5 \%$ & $100 \%$ \\
12 & $25 \%$ & $100 \%$ \\
13 & $75 \%$ & $100 \%$ \\
14 & $25 \%$ & $85.7 \%$ \\
15 & $62.5 \%$ & $85.7 \%$ \\
16 & $62.5 \%$ & $100 \%$ \\
17 & $25 \%$ & $100 \%$ \\
18 & $75 \%$ & $100 \%$ \\
19 & $100 \%$ & $100 \%$ \\
\hline
\end{tabular}

Table 2. Summary of Paired Samples Correlations.

\begin{tabular}{lllll}
\hline & & N & Correlation & Sig \\
\hline Pair 1 & Pre-Percentage \& Post Percentage & 8 & .760 & .029 \\
\hline
\end{tabular}

Note: Numbers are in $\%$ of respondents. Significance $<.05, \mathrm{n}=8$

Following the in-service classes, significant changes were noted in participant's knowledge regarding WIC approved items.

\section{Discussion}

Research indicates that proper nutrition is vital in pregnant women and among children to aid in normal and healthy development. WIC provides resources; however, there are education and knowledge barriers that may hinder recipients from purchasing nutrient rich items that are available through the WIC EBT card program. WIC recipients' complaints indicated there were challenges identifying WIC-allowable items throughout the store. Recipients also reported perceived stigmatization during the checkout process. Study participants described a learning curve in successful use of WIC in retail environments over time. Study participants also reported acceptance of restrictions, such as a requirement to purchase the least expensive brand. Dissatisfaction with the retail experience may lead to the underutilization of WIC benefits or program exit [7]. There is an identified need to educate WIC recipients. Therefore, it is vital to empower individuals with the knowledge needed to enter WIC approved vendors and purchase the necessary qualified items with the WIC EBT card. At the conclusion of the study the following were noted:

1) Participants were comfortable shopping with the WIC EBT Card (Figure 1).

2) However, informational sessions should be offered that identifies WIC approved items or any changes to approved items.

3) In qualitative responses participants noted after the classes...

a) "I dislike not having the option to have substitutions if the approved items are not available." 
b) "Items offered by WIC continues to improve and I'm thankful."

4) A significant increase in knowledge was observed following the class (Tables $1 \& 2$ ).

There is a need to provide further education to WIC participants as a safety guard to ensure that participants have a thorough understanding of all resources available to them. For instance, many participants stated they were not aware that WIC offered an app they could use to identify approved foods before checking out. Likewise, others stated they were aware of the app but did not know how to employ the app. Moreover, WIC participants are currently using the Internet and smartphones to access nutrition information and show a desire to communicate with WIC staff through apps. In Texas, because $86 \%-90 \%$ of WIC participants own smartphones, a WIC smartphone app could be an effective approach for delivering nutrition education and promoting WIC target health behaviors-healthy eating, breast feeding, and physical activity [15]. This supports the argument that recipients need to be informed of the app and educated on how to use the app. Doing so could help to alleviate stress during the checkout process.

\section{Conclusion}

This paper makes a valuable contribution to the literature regarding WIC benefits. This paper highlights the importance of recipients thoroughly understanding what WIC benefits are available. Accordingly, this article strives to remove the gap that exists among benefits available and benefits retrieved. There have been numerous papers that addressed the benefits offered, health benefits, and food insecurity issues but none have dedicated to understanding if recipients understand the brands, sizes, etc. so that recipients may retrieve the items offered. Analysis on this issue highlighted the need for further education to improve or possibly eliminate the percentage of unclaimed benefits.

\section{Declarations}

\section{Abbreviations}

Women, Infant, and Children (WIC); Electronic Benefit Transfer (EBT); United States Department of Agriculture (USDA); Institutional Review Board Approval (IRB)

\section{Ethics Approval and Consent to Participate}

The study protocol was approved by the University of Southern Indiana Institutional Review Board (Reference \#2017-177-NH, Dr. Katherine Draughon; Executive Director-OSPRA) and the Green River District Health Department: Public Health Director. All participating subjects signed informed consent forms.

\section{Consent for Publications}

"Not applicable"

\section{Availability of Data and Material}

All data generated or analyzed during this study are included in this published article in the form of charts and tables. If additional data may be requested from the corresponding author on reasonable request.

\section{Competing Interests}

The author declares there is no competing interests.

\section{Funding}

Funding for this research project was made possible through a Junior Faculty Summer Research grant through the University of Southern Indiana

\section{Authors' Contributions}

I consent as the sole author that the information presented is my original work.

\section{Acknowledgements}

Funding for this project was made possible through a Junior Faculty Summer Research grant through the University of Southern Indiana. Special thanks to the participants, Principal Rob Carroll, Audubon Kids Zone Community Center, Henderson Kentucky WIC Office, and Dr. Erin Reynolds.

\section{References}

[1] United States Department of Agriculture: Food and Nutrition Services. http://www.fns.usda.gov/wic/women-infants-andchildren-wic. (2015). Accessed on 8 Aug 2017.

[2] Chiasson, M. A. Findley, S. E. Sekhobo, J. P. Scheinmann, R. Edmunds, L. S. Faly, A. S. \& McLeod, N. J. (2013). Changing WIC changes what children eat. Obesity, 21 (7), 1423-1429. doi: http://dx.doi.org/10.1002/oby.20295

[3] Oliveira V, Frazao E. The WIC Program: Background, Trends, and Economic Issues, 2009 Edition. Washington, DC: US Department of Agriculture, Economic Research Service; 2009. Economic Research Report no. 73.

[4] Fingar, K. R. Lob, S. H. Dove, M. S. Gradziel, P. \& Curtis, M. P. (2017). Reassessing the association between WIC and birth outcomes using a fetuses-at-risk approach. Maternal and Child Health Journal, 21 (4), 825-835. doi: http://dx.doi.org.lib-proxy.usi.edu/10.1007/s10995-016-21769

[5] Gregory, E. F. Gross, S. M. Nguyen, T. Q. Butz, A. M. \& Johnson, S. B. (2016). WIC participation and breastfeeding at 3 months postpartum. Maternal and Child Health Journal, 20 (8), 1735-1744. doi: http://dx.doi.org/10.1007/s10995-0161977-1

[6] Toy, S. Tripodis, Y. Yang, K. Cook, J. \& Garg, A. (2016). Influence of Maternal Depression on WIC Participation in Low-Income Families. Maternal and Child Health Journal, 20 (3), 710-9. 
[7] Chauvenet, C. De Marco, M. Barnes, C. \& Ammerman, A. (2019). WIC Recipients in the Retail Environment: A Qualitative Study Assessing Customer Experience and Satisfaction. Journal of the Academy of Nutrition and Dietetics, 119 (3), 416-424. e2.

[8] Gittelsohn, J. Laska, M. N. Andreveva, T. Foster, G. Rose, D. Tester, J. \&...Ayala, G. X. (2012). Small Retailer Perspectives of the 2009 Women, Infants and Children Program Food Package Changes. American Journal of Health Behavior, 36 (5), 655-665. Doi: 10.5993/AJHB.36.5.8.

[9] Cobb, L. K. Anderson, C. A. M. Appel, L. Jones-Smith, J. Bilal, U. Gittelsohn, J. \& Franco, M. (2015). Baltimore city stores increased the availability of healthy food after WIC policy change. Health Affairs, 34 (11), 1849-5A. doi: http://dx.doi.org/10.1377/hlthaff.2015.0632

[10] Robinson, C. (2016). Family composition and the benefits of participating in the special supplemental nutrition program for women, infants, and children (WIC). Eastern Economic Journal, 42 (2), 232-251. doi: http://dx.doi.org.libproxy.usi.edu/10.1057/eej.2014.43

[11] Noia, J. D. Monica, D. Sikorskii, A. \& Karen, W. C. (2017). Outcomes of a randomized controlled trial of nutrition education to promote farmers market fruit and vegetable purchases and consumption among women enrolled in the special supplemental nutrition program for women, infants, and children (WIC). BMC Nutrition, 3 doi: http://dx.doi.org/10.1186/s40795-017-0172-0

[12] Tofail, F. Persson, L. A. Arifeen, S. E. Hamadani, J. D. Mehrin, F. Ridout, D. Ekstrom, E. C. Huda, S. N. \& Grantham-McGregor, S. M. (2008). Effects of prenatal food and micronutrient supplementation on infant development: A randomized trial from the Maternal and Infant Nutrition Interventions, Matlab (MINIMat) studyl'2'3. American Journal of Clinical Nutrition, 87, 3, 704-711.

[13] Kowaleski-Jones, L. \& Duncan, G. J. (2002). Effects of participation in the WIC program on birthweight: Evidence from the national longitudinal survey of youth. American Journal of Public Health, 92 (5), 799-804. Retrieved from https://login.libproxy.usi.edu/login?url=http://search.proquest. com.libproxy.usi.edu/docview/215106043? accountid $=14752$

[14] Metallinos-Katsaras, E. Gorman, K. Wilde, P. \& Kallio, J. (2011). A longitudinal study of WIC participation on household food insecurity. Maternal and Child Health Journal, 15 (5), 627-33.

[15] Biediger-Friedman, L. Silva, M. \& Smith, K. (2018). A Focus Group Study Observing Maternal Intentions to Use a WIC Education App. American Journal of Health Behavior, 42 (6), 110-123. https://doi.org/10.5993/AJHB.42.6.11. 